\title{
Idosos na pandemia, vulnerabilidade e resiliência
}

\author{
Older adults in a pandemic, vulnerability and resilience
}

Desde o início na pandemia de COVID-19, em 2020, pessoas idosas foram identificadas como pertencendo a um grupo de risco. A recomendação na maioria dos países foi de que mantivessem o máximo possível de isolamento, além de uso de máscaras e as medidas de higienização indicadas para todos. Alguns mantêmse isolados desde então, há quase um ano, sem ver ou abraçar seus entes queridos, se vivem sós. Os que residem em abrigos estão impossibilitados de encontrar com seus familiares. Muitos passaram a viver em um mundo sem abraços, de comemorações e compras online, por vezes tendo que lidar com redes sociais que não dominam. As dificuldades ainda se agravam para os que não têm condições financeiras estáveis.

Estou nessa categoria de idosos, porque tenho 74 anos e vivo sozinha. Passei cinco meses sem me encontrar com meu filho que mora no Brasil e minha netinha. Minha filha e sua família moram em Londres. Tenho uma cunhada de 88 anos que também vive só e que passou um ano em isolamento quase total. A situação de idosos nessa pandemia é algo que está sempre em minha mente, não só por minha situação pessoal, mas por ser uma pesquisadora de psicologia do desenvolvimento, interessada em todo o ciclo vital, da concepção até a morte.

Ao preparar uma palestra para a aula inaugural comemorativa dos 30 anos do Programa de Pós-Graduação em Psicologia Social do IP da UERJ, escolhi o tema: Ciência e psicologia social em tempos de pandemia. Para tal, fiz uma revisão e encontrei muitos artigos científicos, mas, naquela ocasião, nenhum deles sobre os efeitos psicológicos da pandemia em idosos. Diante do convite para escrever este Editorial, voltei à busca. Alguns de seus resultados me surpreenderam positivamente, mas devem ser considerados com cautela, necessitando de mais investigações.

Antes de quaisquer comentários, deve ser considerada a variabilidade dessa população, assim como da de outras faixas etárias, em termos de condições de saúde, moradia, nível educacional, escolaridade, rede de apoio, experiência de vida, crenças e valores, presença de demência ou não etc. Quase impossível generalizar. Importante pensar também na desigualdade social endêmica em nosso país, que atinge os idosos. No entanto, algumas reflexões podem ser feitas.

Os primeiros impactos que se pode pensar são devidos a ser considerado(a) pertencendo a grupos de risco e mais vulnerável. Sentimentos de medo, ansiedade, estresse e mesmo raiva podem ser esperados e precisam ser acolhidos. Além disso, as condições de isolamento trazem solidão e podem afetar o bemestar e a saúde mental de idosos. Em revisão sistemática realizada por Tappenden \& Tomar ${ }^{1}$, foi observado que "....sentimentos de isolamento ou perda de relações sociais indicou ter implicações para o declínio em cognição, ânimo e sensibilidade a ameaças" (p. 25-26). Podem levar ao aumento de cortisol e diminuição 
de imunidade, afetando o sono e provocando o aumento de peso. Assim, efeitos na saúde física e mental são esperados. Javadi e Nateghi ${ }^{2}$ também mencionam esses efeitos.

Isso, certamente, é preocupante e exige medidas protetivas de pessoas idosas. Ao mesmo tempo, há alguma evidência, tal como discutido por Vahia, Jeste \& Reynolds III' ${ }^{3}$, de que pelo menos uma parte dessa população apresenta maior resiliência do que outros grupos. Segundo eles, a resiliência pode ser atribuída a fatores internos ou externos. No primeiro caso, a capacidade cognitiva, traços de personalidade, saúde física e diferenças na reação a estresse. No segundo, aspectos como status social e estabilidade financeira. Poderse-ia incluir a disponibilidade de uma rede de apoio e algum domínio de recursos eletrônicos e media social.

Os autores discutem ainda um aspecto particularmente interessante, com base em um estudo com 482 adultos idosos e de meia idade sobre solidão e sabedoria. Trata-se da sabedoria, segundo eles "um traço de personalidade complexo, constituído de componentes específicos como empatia, compaixão, regulação emocional, a capacidade de autorreflexão, capacidade de decisão, mesmo aceitando a incerteza e diversidade de perspectivas, aconselhamento social e espiritualidade" (p. 2254). Compaixão parece ser um elemento chave.

A sabedoria parece favorecer a resiliência, que é fundamental para lidar com crises diversas, em especial crises tão longas e complexas como a que estamos vivendo. É uma capacidade que pode ser desenvolvida e envolve a capacidade que as pessoas têm de se adaptarem às dificuldades, traumas, ameaças, tragédias ou fontes significativas que podem provocar estresse. Zanon et $\mathrm{al}^{4} \mathrm{a}$ incluem como um dos conceitos da psicologia positiva a serem utilizados na intervenção ao sofrimento psíquico causado pela pandemia de COVID 19 e suas consequências.

Um documento da Organização Mundial de Saúde ${ }^{5}$ enumera algumas das preocupações de pessoas idosas e seus cuidadores e como agir diante delas: necessidade de apoio prático e emocional através de redes informais e profissionais de saúde; disseminação de informações simples e claras de como reduzir o risco de infecção; aprender práticas simples de atividades físicas diárias; manter contato com pessoas queridas por telefone ou meios digitais (receber ajuda para uso desses meios), manter rotinas regulares tanto quanto possível ou desenvolver novas.

Uma publicação do serviço de Saúde Pública inglês, citado por Tappenden \& Tomar $^{1}$ complementa essas recomendações promotoras de saúde. Segundo este documento, criar uma rotina diária oferece estrutura e metas e uma rotina semanal garante uma boa mistura de descanso e lazer; identificar o que desencadeia desânimo para reduzir esses gatilhos e as sensações negativas; cuidar da saúde e bem-estar, mantendo uma dieta saudável e exercitando-se regularmente para manter a saúde física e mental; manter contado com outros, para reduzir a solidão e o isolamento.

Pode-se observar, assim, que apesar de idosos representarem um grupo em geral mais vulnerável, nem sempre reagem negativamente às condições adversas dessa pandemia. Com sua sabedoria, podem apresentar resiliência e manter sua saúde mental e razoável bem-estar. É preciso estar atento às suas necessidades e oferecer proteção e cuidado para promover sua saúde e diminuir o sofrimento psíquico inerente à situação de ameaça e de isolamento. Essas recomendações necessitam estar inscritas em um cenário mais amplo de cuidado a idosos.

"Urge reforçarmos políticas para a atenção primária em saúde, criar estratégias de monitoramento remoto, garantir insumos de sobrevivência, oferecer orientações concretas e suporte às ILPIs, cuidar dos idosos que vivem em situação de rua, apoiar os idosos que cuidam de idosos ou que ainda trabalham na informalidade para sua subsistência, além de garantir abordagem humanitária e cuidados paliativos, quando necessário" (Kalache et al, 2020) .

Maria Lucia Seidl de Moura Professor Titular do Instituto de Psicologia da Universidade do Estado do Rio de Janeiro (UERJ). Rio de Janeiro, RJ, Brasil. 


\section{REFERÊNCIAS}

1. Tappenden I, Tomar R. Mental health impacts of social isolation in older people during COVID pandemic. Progress Neurol Psychiatry. 2020;24(4):25-9.

2. Javadi SMH, Nateghi N. COVID-19 and its psychological effects on the elderly population. Disaster Med Public Health Prep. 2020;14(3):40-1.

3. Vahia IV, Jeste DV, Reynolds III CF. Older adults and the mental health effects of COVID-19. J Am Med Assoc. 2020;324(22):2253-4. Disponível em: https://doi.org/10.1001/jama.2020.21753

4. Zanon C, Dellaza-Zanon LL, Wechsler SM, Farbetti RR, Rocha KN. COVID-19: implicações e aplicações da psicologia positiva em tempos de pandemia. Estud Psicol (Campinas). 2020;37:e200072. Disponível em: https://doi. org/10.1590/1982.

5. World Health Organization. Mental Health and psychological considerations during the COVID-19 outbreak [Internet]. Geneva: WHO; 2020 [acesso em 10 mar. 2021]. Disponível em: www.who.int/docs/default-source/ coronaviruse/mental-health-considerations.pdf?sfvrsn=6d3578af_2

6. Kalache A, da Silva A, Giacomin KC, de Lima KC, Ramos LR, Louvison M, et al. Envelhecimento e desigualdades: políticas de proteção social aos idosos em função da Pandemia Covid-19 no Brasil. Rev Bras Geriatr Gerontol. 2020;23(6):e200122. 